\title{
Mice Lacking Ataxin-1 Display Learning Deficits and Decreased Hippocampal Paired-Pulse Facilitation
}

\author{
Antoni Matilla, ${ }^{1}$ Erik D. Roberson, ${ }^{2}$ Sandro Banfi, ${ }^{1}$ Joanella Morales, ${ }^{3}$ Dawna L. Armstrong, ${ }^{4}$ \\ Eric N. Burright, ${ }^{7}$ Harry T. Orr, ${ }^{7}$ John D. Sweatt, ${ }^{2}$ Huda Y. Zoghbi, ${ }^{1,2,3,6}$ and Martin M. Matzuk ${ }^{3,4,5}$ \\ Departments of ${ }^{1}$ Pediatrics, ${ }^{2}$ Neuroscience, ${ }^{3}$ Molecular and Human Genetics, ${ }^{4}$ Pathology, and ${ }^{5} \mathrm{Cell}$ Biology, and \\ ${ }^{6}$ Howard Hughes Medical Institute, Baylor College of Medicine, Houston, Texas 77030, and 7 University of \\ Minnesota, Minneapolis, Minnesota 55455
}

Spinocerebellar ataxia type 1 (SCA1) is a neurodegenerative disorder characterized by ataxia, progressive motor deterioration, and loss of cerebellar Purkinje cells. To investigate SCA1 pathogenesis and to gain insight into the function of the SCA1 gene product ataxin-1, a novel protein without homology to previously described proteins, we generated mice with a targeted deletion in the murine Sca1 gene. Mice lacking ataxin-1 are viable, fertile, and do not show any evidence of ataxia or neurodegeneration. However, Sca1 null mice demonstrate decreased exploratory behavior, pronounced deficits in the spatial version of the Morris water maze test, and impaired performance on the rotating rod apparatus. Furthermore, neurophysiological studies performed in area CA1 of the hippocampus reveal decreased paired-pulse facilitation in Sca1 null mice, whereas long-term and post-tetanic potentiations are normal. These findings demonstrate that SCA1 is not caused by loss of function of ataxin-1 and point to the possible role of ataxin- 1 in learning and memory.

Key words: spinocerebellar ataxia type 1; ataxin-1; neurobehavior; hippocampus; cerebellum; paired-pulse facilitation
Spinocerebellar ataxia type 1 (SCA1) is an autosomal dominant neurodegenerative disorder characterized by progressive ataxia and selective neuronal loss within the cerebellar cortex and brainstem (Zoghbi and Orr, 1995). The genetic basis of SCA1 involves an expansion of an unstable $\mathrm{CAG}$ trinucleotide repeat located within the coding region of the SCA1 gene (Orr et al., 1993; Banfi et al., 1994). SCA1 encodes the novel 792-869 amino acid protein ataxin-1, whose size depends on the number of glutamine residues encoded by the CAG repeat. Both the wild-type and mutant proteins are translated and detected in tissues of affected individuals (Servadio et al., 1995).

The murine Scal gene is highly homologous to the human gene ( $89 \%$ identity at the protein level), suggesting that the proteins have evolutionarily conserved functions (Banfi et al., 1996). RNA in situ hybridization reveals a wide pattern of expression of Sca1, with the highest levels in the neurons of the dentate gyrus, hippocampal pyramidal cells, and cerebellar Purkinje cells (Banfi et al., 1996; Gossen et al., 1996). Interestingly, a transient burst of Scal expression is seen in Purkinje cells at postnatal day 14 when the murine cerebellar cortex becomes physiologically functional

Received Dec. 22, 1997; revised April 24, 1998; accepted April 28, 1998.

This work was supported by National Institutes of Health Grants NS27699 (H.Y.Z.) and NS33718 (H.T.O.), and by the Baylor College of Medicine Mental Retardation Research Center. Antoni Matilla was supported by a postdoctoral fellowship from the Spanish Ministerio de Educación y Ciencia. We are grateful to Mary Elizabeth Bach, Linda Crnic, Robert Gerlai, Karl Giese, Myrna Khan, Richard Paylor, O'Brian Smith, and Eduardo Soriano for helpful discussions and suggestions, to Daniel Johnston and James Patrick for critical reading of this manuscript, and to V. Brandt for editorial suggestions. We thank Allan Bradley for the gift of the AB2.1 ES cells, and B. Antalffy, J. Dong, Q. Guo, D. Larkin, and N. Lu for expert technical assistance.

Correspondence should be addressed to Dr. H. Y. Zoghbi, Howard Hughes Medical Institute, Baylor College of Medicine, One Baylor Plaza, Room T-807, Houston, TX 77030.

Dr. Banfi's present address: Telethon Institute of Genetics and Medicine, Via Olgettina, 58, 20100 Milan, Italy.

Copyright (C) 1998 Society for Neuroscience $\quad 0270-6474 / 98 / 185508-09 \$ 05.00 / 0$
(Banfi et al., 1996). Cerebellar Purkinje cells and hippocampal pyramidal cells show the highest levels of ataxin-1 expression (H. Y. Zoghbi and D. L. Armstrong, unpublished observations), suggesting that ataxin-1 might play a role in their development and function.

In transgenic mice, overexpression of mutant human ataxin-1 with 82 glutamines selectively in Purkinje cells causes loss of these cells and an ataxic phenotype (Burright et al., 1995). The mutant protein thus appears to gain a novel toxic function that underlies the pathogenesis of SCA1. To gain insight into the function of wild-type ataxin-1, a widely expressed protein with no known homologies, and to determine that SCA1-associated ataxia is not caused by loss of function of ataxin-1, we generated Scal null mice using gene-targeting technology.

\section{MATERIALS AND METHODS}

Generation of Sca1 null mice. The murine homolog of Sca1 was isolated and characterized previously (Banfi et al., 1996). Corresponding genomic clones were obtained from a genomic library prepared from $129 / \mathrm{SvEv}$ strain (Stratagene, La Jolla, CA). The targeting vector (see Fig. $1 A$ ) contains $8.1 \mathrm{~kb}$ of homology flanking exon 8 of the $S c a 1$ coding sequence. The deletion-targeting vector contains, from left to right in Figure $1 A$, an MC1-thymidine kinase expression cassette, a $4.4 \mathrm{~kb}$ Bam HI fragment of 5' Scal homology, a phosphoglyceratekinase hypoxanthine phosphoribosyl transferase (PGK-hprt) expression cassette (transcription from right to left), and $3.5 \mathrm{~kb}$ of $3^{\prime}$ Scal homology (ApaI-BamHI Scal fragment). The targeting construct DNA was linearized with SalI $(25 \mu \mathrm{g})$ and electroporated (Gene Pulser; Bio-Rad, Hercules, CA) into $1 \times 10^{7}$ hprt-negative AB2.1 embryonic stem (ES) cells derived from 129/SvEv background, as described previously (Matzuk et al., 1992). ES cell clones were selected in M15 medium containing hypoxanthine, aminopterin, and thymidine and 1-(2'-deoxy-2'-fluoro- $\beta$-D-arabinof uranosyl)-5iodouracil. ES cell DNA was digested with HindIII (New England Biolabs, Beverly, MA) and electrophoresed through a $0.8 \%$ agarose gel. After transfer, the membranes were hybridized with ${ }^{32} \mathrm{P}$-labeled $5^{\prime}$ or $3^{\prime}$ genomic flanking probes (see Fig. $1 A$ ). Autoradiographic film was exposed for $2-3 \mathrm{~d}$ at $-80^{\circ} \mathrm{C}$ and subsequently developed. Two ES cell clones, Sca1-11-E5 and Sca1-11-B4, were used to produce chimeras by 
microinjection into C57BL/6J blastocysts and implantation into pseudopregnant foster mothers, as described previously (Matzuk et al., 1992). Both ES cell clones generated high levels of chimerism (129/SvEvderived agouti coat color pigmentation $>60 \%$ ), and 23 male chimeras were identified. Mating of chimeric male mice with C57BL/6J females yielded agouti hybrid background offspring, about half of which carried the null allele as revealed by Southern blot analysis of genomic tail DNA. Homozygous animals for the null allele were generated by mating F1 heterozygous (C57Bl/6J-129/SvEv) mice from the same litter. Mutant mice of pure $129 / \mathrm{SvEv}$ inbred background were also generated by mating chimeric mice with 129/SvEv females.

Western blot analysis. Protein extracts from mouse brain tissue were prepared, as described previously (Burright et al., 1995). Immunoblots were probed with sera containing antibodies that recognize ataxin-1, as described previously (Servadio et al., 1995).

Neurobehavioral studies. Neurobehavioral studies were performed on F2 Sca1 mutant mice and control littermates from both C57Bl/6J-129/ SvEv hybrid and 129/SvEv inbred genetic backgrounds. A minimum of 10 null and 10 control mice were used in all of the studies.

Footprint analysis. Each mouse was placed at the entry of a dark tunnel made of wood $(9 \times 6 \times 40 \mathrm{~cm})$ after its hindpaws were dipped in blue ink. The length of time it took to emerge from the tunnel (latency) was measured. The footprints were recorded on a clean sheet of white paper placed on the floor of the tunnel and were used to measure stride length (by averaging the distance, length, and width between two consecutive steps) and left-right step alternation coefficient.

Open field test. Mice were placed in a $60 \times 60 \mathrm{~cm}$ open arena and allowed to move under indirect illumination for 15 min during 6 consecutive days. The surface of the arena was cleaned with $70 \%$ ethanol and air-dried between mice. On the fourth day, three different objects were placed in the center of the arena. We measured the total distance traversed and the ambulatory, stereotypic, and resting times for three intervals of 5 min each using the Videomex-V system (Columbus Instruments, Columbus, $\mathrm{OH}$ ).

Elevated plus maze test. Mice were placed in the center of a plus-shaped maze elevated $38.5 \mathrm{~cm}$ from the floor with two open and two closed arms, each $30 \mathrm{~cm}$ long and $5 \mathrm{~cm}$ wide (Lafayette Instrument Co., Lafayette, IN). We analyzed general mouse activity for $5 \mathrm{~min}$. The percent of visits and time spent in open arms was recorded and compared with the percent of visits and time spent in closed arms.

Morris water maze test. A large circular pool $(152 \mathrm{~cm}$ in diameter $)$ was filled with water and made opaque with $450 \mathrm{gm}$ of white paint (powder tempera). In the hidden platform version, a $14-\mathrm{cm}$-diameter platform was submerged $1 \mathrm{~cm}$ below the water surface. Mice were initially guided to the platform and allowed to stay on it for $1 \mathrm{~min}$; subsequently, they were placed in the pool and were allowed to search for the platform for $1 \mathrm{~min}$ using four visible external cues (Morris et al., 1982). The latency (time) to find the platform was recorded for each block of four trials, and each trial was initiated from a different quadrant. The latencies of four consecutive trials were averaged and used for statistical analysis. Mice were allowed to navigate four trials per day for 10 consecutive days. After $10 \mathrm{~d}$ of this distributed training, the first memory probe test was performed. The platform was removed, and the mice were allowed to search for it for $1 \mathrm{~min}$. Control mice failed to selectively search the quadrant in which the platform had been located during the training period, so an additional distributed training of 4 more days with four trials each was performed. Because the control mice failed the second memory probe test, a massed training procedure of 3 more days with 12 trials every day was performed (Silva et al., 1992; Abeliovich et al., 1993). Subsequently, the mice were subjected to a third memory probe test. All data were recorded using the Videomex-V system (Columbus Instruments). In the nonspatial version of the Morris water maze test, the external visible cues were hidden by a curtain surrounding the pool, and a submerged 16-cm-diameter platform was cued by placing a symmetrically painted black and white golf ball on the center of the platform. Mice of pure $129 / \mathrm{SvEv}$ background were trained $3 \mathrm{~d}$ with three blocks of four trials each day. The position of the platform was changed pseudorandomly in every trial. The latencies to find the platform, as well as distances and speed performance, were recorded.

Rotating rod test. An accelerated rotating rod test allowed us to evaluate coordination and motor skill acquisition (type 7650; Ugo Basile, Milan, Italy). Mice were placed on the rod $(3 \mathrm{~cm}$ diameter, $30 \mathrm{~cm}$ long) in four trials every day for a period of 4 or $7 \mathrm{~d}$. Each trial lasted $10 \mathrm{~min}$. The rod accelerated from 4 to $40 \mathrm{rpm}$ in $5 \mathrm{~min}$. The time the mice spent on the rod without falling was recorded.
Electrophysiological studies. Hippocampal slices from 6-week-old mice were prepared, as described previously (Roberson and Sweatt, 1996). Electrophysiological recordings were performed at $24^{\circ}$; test stimuli were delivered to the Schaffer collateral-commissural pathway in area CA1 with a bipolar Teflon-coated platinum electrode at $0.05 \mathrm{~Hz}$, and responses from stratum radiatum were recorded. Test stimulus intensity was selected to produce a population EPSP (pEPSP) of $\sim 50 \%$ of maximum. Long-term potentiation (LTP) was induced after at least $20 \mathrm{~min}$ of stable baseline recording by two $1 \mathrm{sec} 100 \mathrm{~Hz}$ tetani, $20 \mathrm{sec}$ apart at the test stimulus intensity. Paired-pulse facilitation (PPF) was elicited at the test stimulus intensity with the recording configuration described above. The maximal slope and peak amplitude of the second EPSP was expressed as a percentage of the first EPSP. In each slice, responses to four pairs of pulses were measured at each interpulse interval with at least 20 sec between pairs of stimuli, and the four repetitions were averaged.

Data analysis. Behavioral scores were subjected to either ANOVA, ANOVA with repeated measures, or multivariate ANOVA when no differences between the variances of control and mutant mice were found by the Levene homogeneity test for the variances. Otherwise, the homologous nonparametric Mann-Whitney $U$ test was used. Statistical analyses were performed using the SPSS software package, version 6.1 for Power Macintosh (SPSS, Inc., Chicago, IL).

\section{RESULTS}

\section{Generation of Sca1 null mice}

Exon 8 of the Scal gene contains the majority of the coding region (amino acids 1-616) and was targeted and deleted in ES cells (Fig. 1A). Twenty-nine percent of ES cell clones (35 of 120) demonstrated the correct $S c a 1$ mutation $\left(S c a 1^{\mathrm{m} 1}\right)$. Heterozygous $\left(S c a 1^{\mathrm{m} 1} /+\right)$ mice were fertile, viable, and indistinguishable from their wild-type (WT) littermates. $S c a 1^{\mathrm{m} 1} /+$ mice were intercrossed to obtain homozygous $S c a 1$-deficient $\left(S c a 1^{\mathrm{m} 1} / S c a 1^{\mathrm{m} 1}\right)$ mice. Genotype analysis of $375 \mathrm{~F} 2$ offspring for these $S c a 1^{\mathrm{m} 1} /+$ intercrosses was consistent with a normal Mendelian frequency of 1:2:1 [86 wild-type (22.9\%), 190 heterozygotes $(50.7 \%)$, and 99 homozygotes $(26.4 \%)$ ]. The $S c a 1^{\mathrm{m} 1}$ mutation was maintained on both $\mathrm{C} 57 \mathrm{Bl} / 6 \mathrm{~J}-129 / \mathrm{SvEv}$ mixed and $129 / \mathrm{SvEv}$ inbred genetic backgrounds. Because the first 616 amino acids of ataxin-1 were deleted by homologous recombination, we used an antibody raised to the remaining $\mathrm{C}$ terminus of the protein (Servadio et al., $1995)$ to confirm that no truncated gene product was being translated. That we found none of the expected $100 \mathrm{kDa}$ ataxin- 1 protein or any partial products in homozygous mice by immunoblot analysis demonstrated that the mutant $S c a 1^{\mathrm{m} 1}$ allele is a null allele (Fig. 1B).

\section{Sca1 null mice appear normal and do not display ataxia}

$S c a I^{\mathrm{m} 1} / S c a I^{\mathrm{m} 1}$ mice are viable, fertile, and display normal life span and somatic development. In contrast to transgenic mice overexpressing ataxin-1 with an expanded repeat, $S c a 1$ null mice (up to 30 months of age) have a normal gait without evidence of ataxia. Brain weights were similar for control and mutant mice. Nissl and hematoxylin-eosin staining revealed no differences in cell number or neurodegeneration in the cerebellum, brainstem, spinocerebellar tracts, or hippocampus in Scal deficient mice (data not shown). Nor did immunohistochemical analysis using antibodies against calbindin, tyrosine hydroxylase, GABA, calretinin, and glial fibrillary acidic protein reveal any difference between control and mutant mice (data not shown).

To see whether ambulatory skill varied, we analyzed footprint tracks from the tunnel test. Scal null mice did not significantly differ from WT mice, demonstrating that the mutant mice were not ataxic (step length in $\mathrm{cm}, 5.17 \pm 0.67$ and $4.99 \pm 1.00$, control vs mutant, respectively; $p=0.60$; step width in $\mathrm{cm}, 3.86 \pm 0.60$ 
A

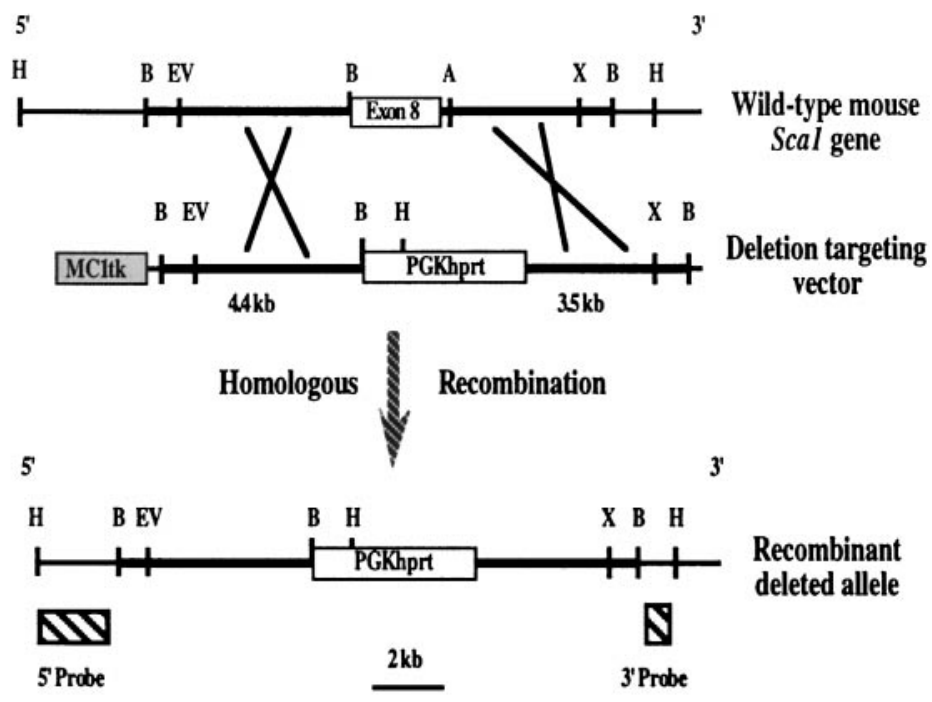

Figure 1. Generation of Sca1 null mice. A, Targeted deletion of exon 8 of the Scal gene by homologous recombination in ES cells. The PGK-hprt expression cassette introduces a novel HindIII site into the targeted locus. Recombinant clones contain 8 or $7.5 \mathrm{~kb}$ HindIII fragments, detected by the $5^{\prime}$ and the $3^{\prime}$ external probes, respectively. PGK, Phosphoglycerate kinase promoter; hprt, hypoxanthine phosphoribosyl transferase; $t k$, thymidine kinase; $H, H i n d I I I ; ~ B, B a m H I$; $E V, E c o$ RV; $X, X b a \mathrm{I}$. B, Western blot analysis of brain extracts using anti-ataxin-1 antibody. Homozygous mutant mice $(-/-)$ had no detectable ataxin-1, whereas heterozygous $(+/-)$ and wild-type $(+/+)$ mice from the same litter showed the expected $100 \mathrm{kDa}$ protein.

and $3.7 \pm 0.35$, respectively; $p=0.40$; left-right step alternation coefficient, $0.184 \pm 0.21$ and $0.18 \pm 0.16$, respectively; $p=0.97$ ).

\section{Neurobehavioral abnormalities in Sca1 null mice Performance in the open field test}

Home cage behavior of mutant mice (gait and general activity) was indistinguishable from that of control mice. However, null mice were consistently easier to handle and catch and were less active when placed in a new cage. This prompted us to evaluate the exploratory behavior and general locomotor activity of these mice in an open field (Crusio et al., 1989). Sca1 null mice from a mixed genetic background (C57Bl/6J-129/SvEv) did not travel as much as controls in the new environment during the first $5 \mathrm{~min}$ interval of the first $\left(F_{(1,34)}=8.087 ; p=0.0075\right)$, second $\left(F_{(1,34)}=\right.$ $6.08 ; p=0.0189)$, and fifth $\left(F_{(1,34)}=4.527 ; p=0.041\right)$ days (Fig. $2 A)$. No significant differences were detected between control and mutant mice in the second and third 5 min intervals in all $6 \mathrm{~d}$ $(p>0.05)$. On the first day, Scal null mice remained in the central area of the field for the first 5 min interval, whereas WT mice reached the periphery in the first minute. On the third day, when control mice became habituated, their level of activity was similar to that of null mice. On the fourth day, both null and WT mice responded to novel objects with increased activity. By the sixth day, when environmental novelty had worn off, the total distance traveled was very similar for both groups $(p>0.05)$. These results could reflect either a decreased exploratory behavior or anxiety in Scal null mice. ANOVA quantified the effect of the mutation $\left(F_{(1,34)}=6.64 ; p=0.015\right)$ and an effect of days in the field $\left(F_{(5,170)}=5.09 ; p<0.0001\right)$, showing that control mice habituated with time (as reflected by a decrease in locomotor activity, $\left.F_{(5,85)}=6.33 ; p<0.0001\right)$, whereas null mice maintained similar levels of activity throughout the entire experiment $\left(F_{(5,85)}\right.$ $=0.71 ; p=0.620)$.

Decreased exploratory behavior was confirmed in inbred 129/
SvEv Sca1 null mice (Fig. 2B). ANOVA with repeated measures detected a significant difference between control and null mice during the first 5 min interval of the first $\left(F_{(1,26)}=4.39 ; p=\right.$ $0.045)$ and fourth $\left(F_{(1,26)}=4.52 ; p=0.043\right)$ days when three novel objects were added to the arena. It also detected a main effect of the days $\left(F_{(5,140)}=3.34 ; p=0.007\right)$. Like mice of a hybrid genetic background, the levels of activity for pure 129/SvEv control and null mice were similar on the sixth day and in the second and third 5 min intervals in all $6 \mathrm{~d}(p>0.05)$. Both WT and mutant $129 / \mathrm{SvEv}$ mice showed less activity overall than corresponding mice of a hybrid C57Bl/6J-129/SvEv genetic background. Post hoc analysis (Student-Newman-Keuls test) detected significant differences between WT mice of a hybrid genetic background and WT mice of a $129 / \mathrm{SvEv}$ inbred background in the first $2 \mathrm{~d}$ $(p<0.05)$.

\section{Performance on the elevated plus maze}

To find out whether the decreased exploratory activity of null mice in the open field test was caused by anxiety, we studied mouse behavior in an elevated plus maze, in which the percentage of open arm entries and the cumulative time spent in open arms measure anxiety independently of activity level (see Materials and Methods) (Lister, 1987). WT mice began exploring the maze immediately after being placed in the center of the platform, but most of the mutant mice stayed longer in the center of the maze, which is consistent with their decreased exploratory behavior in the open field test. Nonparametric analysis of the data of the mixed genetic background confirmed this observation $(U=34$; $p=0.0063)$. There were no significant differences between control and mutant mice of either genetic background with regard to the time spent in the closed and open arms or the percent of visits to each arm (percentage entries to closed arms, $83.38 \pm 26.02$ vs $79.65 \pm 28.6$ for WT and mutant mice of a mixed genetic background, respectively; $p=0.726$; percentage entries to open arms, 
A

\section{C57BI/6J-129/SvEv}

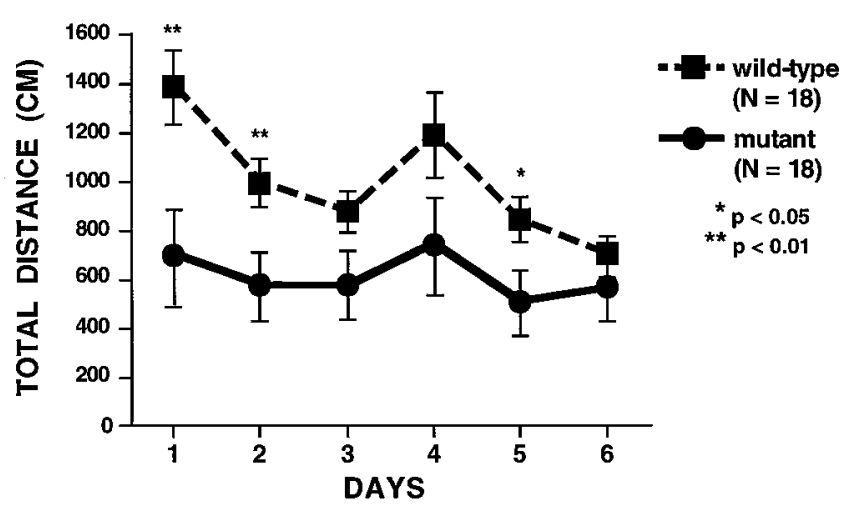

B

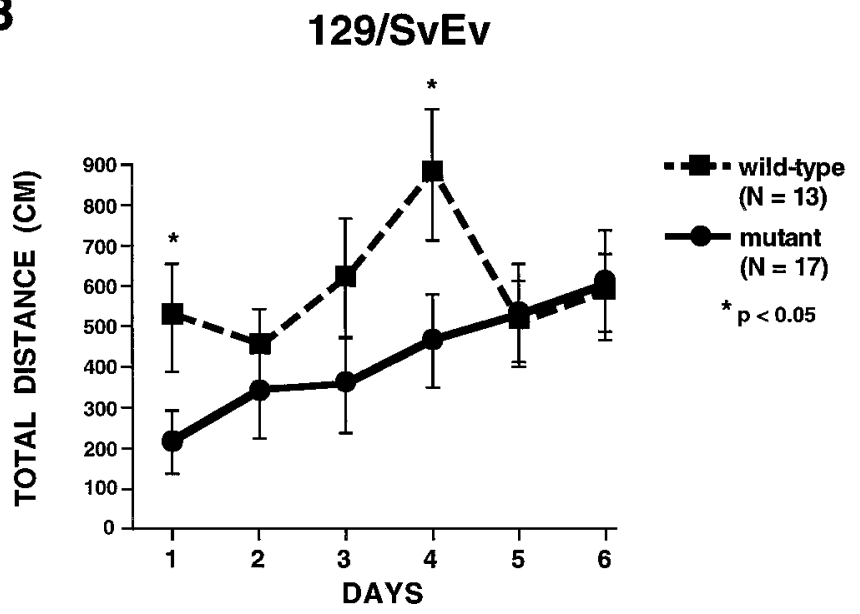

Figure 2. Decreased exploratory behavior of Sca1 null mice in the open field test. Analysis of the total distance traveled by C57Bl/6J-129/SvEv hybrid mice $(A)$ and pure $129 / \mathrm{SvEv}$ inbred mice $(B)$ during the first $5 \mathrm{~min}$ interval for 6 consecutive d. Error bars indicate SEM.

$16.62 \pm 26.02$ vs $20.35 \pm 28.6$, respectively; $p=0.726)$. Similar results were obtained for mice from the $129 / \mathrm{SvEv}$ inbred background (data not shown). These tests confirmed the decreased exploratory activity of mutant mice and excluded the possibility that such behavior resulted from anxiety.

\section{Impaired performance in the spatial version of the Morris} water maze test

Because of the high levels of both the Scal mRNA and ataxin-1 in the hippocampus (Banfi et al., 1996; Gossen et al., 1996; Zoghbi, unpublished observations) and the putative role of this brain formation in exploratory behavior (Crusio et al., 1989), we examined the performance of ataxin-1-deficient mice in the Morris water maze test to determine whether there were additional hippocampal deficits (Morris et al., 1982). No behavioral differences were noted between control and null mice during pretraining. WT and mutant mice from both genetic backgrounds could swim and were motivated to escape to an underwater platform when guided to it. In the hidden platform version of the Morris water maze test, WT mice of a pure $129 / \mathrm{SvEv}$ genetic background had significantly lower escape latencies than mutant mice from the third day onward, indicating spatial learning deficits in the null mice (Fig. 3A). ANOVA with repeated measures showed a significant genotype $\times$ trial interaction $\left(F_{(16,448)}=6.03 ; p<\right.$ $0.0001)$, a main effect of genotype $\left(F_{(1,28)}=31.62 ; p<0.0001\right)$ confirming that WT mice had lower escape latencies than the mutants, and an effect of trial $\left(F_{(16,448)}=8.04 ; p<0.0001\right)$ showing that WT mice latency decreased with training $\left(F_{(16,192)}\right.$ $=8.75 ; p<0.0001)$, but that of null mice $\operatorname{did} \operatorname{not}\left(F_{(16,256)}=1.27\right.$; $p=0.218)$. No significant differences between WT and mutant mice in the total distance traveled were found in the first $3 \mathrm{~d}$ (first day, $F_{(1,28)}=0.297 ; p=0.59$; second day, $F_{(1,28)}=0.298 ; p=$ 0.589 ; third day, $\left.F_{(1,28)}=2.9 ; p=0.099\right)$. In the probe test that followed a massed training procedure (see Materials and Methods), ANOVA with repeated measures showed that WT mice spent more time in the quadrant where the platform was located $\left(F_{(3,36)}=8.43 ; p<0.0001\right)$, but null mice spent similar times in all quadrants $\left(F_{(3,48)}=1.4 ; p=0.255\right)$ (Fig. $\left.3 B\right)$. ANOVA also detected significant differences between WT and mutant mice in the time spent in the first quadrant $\left(F_{(1,28)}=17.66 ; p=0.0002\right)$ where the platform was located, and in the third quadrant $\left(F_{(1,28)}\right.$ $=6.77 ; p=0.0146)$ where mice were introduced, but not in the other quadrants. Finally, WT mice had more platform crossings in the target quadrant compared with the other three quadrants $(6.69 \pm 3.225$ vs $4.051 \pm 1.42 ; p=0.001)$. In contrast, null mice did not have a significant increase in platform crossings for the target quadrant $(4.177 \pm 2.604$ vs $4.196 \pm 0.471 ; p=0.954)$. Similar results were found with null mice of a hybrid genetic background (data not shown), confirming that they experienced spatial learning deficits as well.

The visible platform version of the Morris water maze test was used to assess nonspatial learning in Scal mutant mice and to rule out the possibility that the spatial learning deficits detected in null mice might actually be a product of deficient escape motivation or impairment of vision and/or motor skills. Normal mice use the visual cues to escape from the water, and this simple associative nonspatial task is believed to be independent of hippocampal function (Morris et al., 1982). In analyzing the latencies of escape from the water, ANOVA with repeated measures detected a significant genotype $\times$ block interaction $\left(F_{(8,168)}=2.72 ; p=\right.$ $0.008)$ and an effect of the block $\left(F_{(8,168)}=35.64 ; p<0.001\right)$, without detecting an effect of the mutation $\left(F_{(1,21)}=4.32 ; p=\right.$ $0.05)$. Mutant mice were slower in associative learning during the first three blocks than control mice (first block, $F_{(1,21)}=4.72 ; p=$ 0.04 ; second block, $F_{(1,21)}=8.86 ; p=0.007$; third block, $F_{(1,21)}=$ 7.93; $p=0.01)$, but not from the fourth block $(p>0.05)$ (Fig. $3 C)$. Null mice were slower in the first block $\left(F_{(1,21)}=22.37 ; p=\right.$ $0.0001)$, and they traveled longer distances in blocks 2 and 3 (block 2, $F_{(1,21)}=4.88 ; p=0.038$; block $3, F_{(1,21)}=8.63 ; p=$ $0.008)$. When the data from the entire experiment were considered together, however, we found no significant differences between WT and null mice in distance traveled $\left(F_{(1,21)}=3.96 ; p=\right.$ 0.06 ) or speed (WT mice, $20.26 \pm 2.623$; null mice, $21.15 \pm 3.9$; $\left.F_{(1,21)}=0.4 ; p=0.532\right)$. This shows that the poor performance of the null mice in the spatial version of the Morris water maze test is indeed attributable to spatial learning deficits and not visual or motor impairment.

\section{Performance of null mice on the rotating rod apparatus}

Because the $S c a 1$ gene is highly expressed in the cerebellum (Banfi et al., 1996; Gossen et al., 1996) and cerebellar Purkinje cells are the target cells in SCA1 pathology (Zoghbi and Orr, 1995), we analyzed the coordination and motor skill acquisition of Scal null mice on the rotating rod test (Jones and Roberts, 1968). Mice were evaluated at both 5 weeks and 6-9 months of 


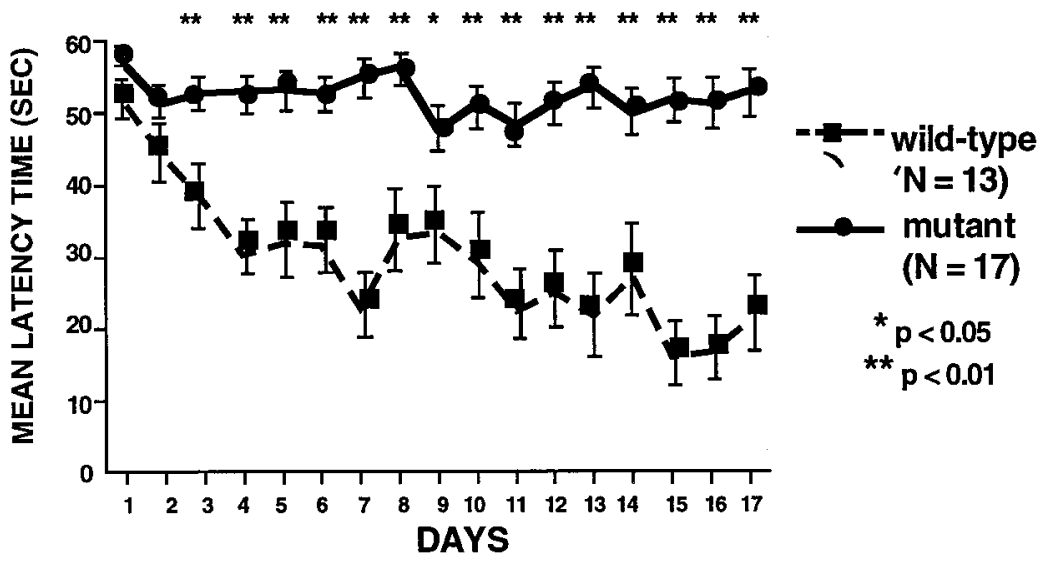

B

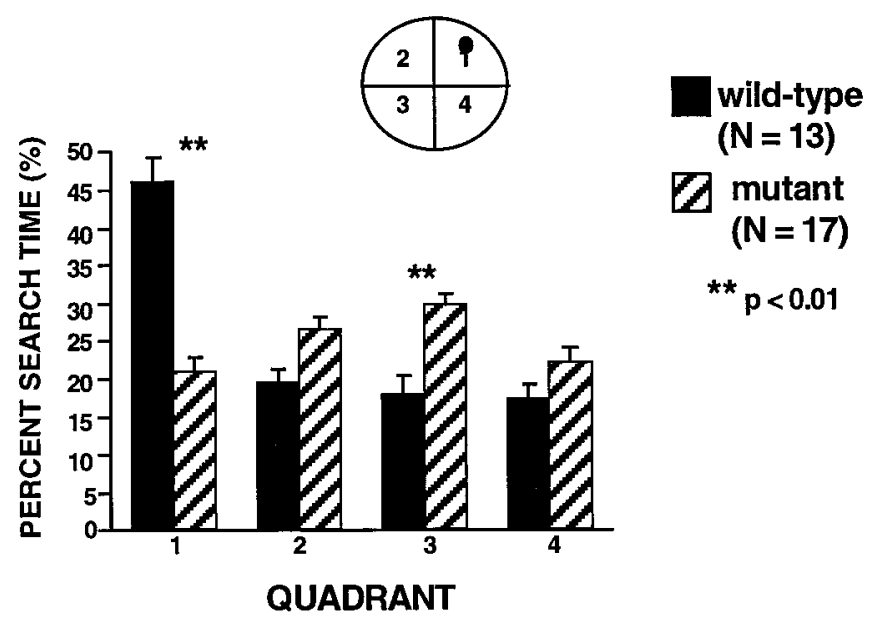

Figure 3. Morris water maze test results for wild-type and Sca1 null mice of a pure $129 / \mathrm{SvEv}$ genetic background. Mean escape latencies $(A)$ and percentage of time spent in the four quadrants $(B)$ in the hidden platform version of the Morris water maze during the last memory probe trial. $C$, Performance in the visible platform version of the Morris water maze test. Similar results were obtained with mice of mixed genetic background. Error bars indicate SEM.

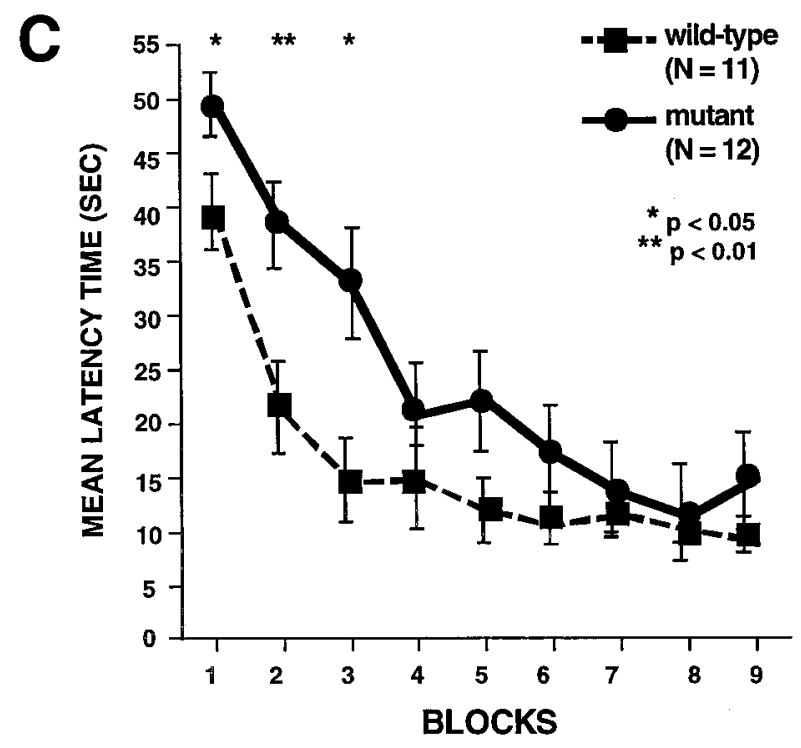



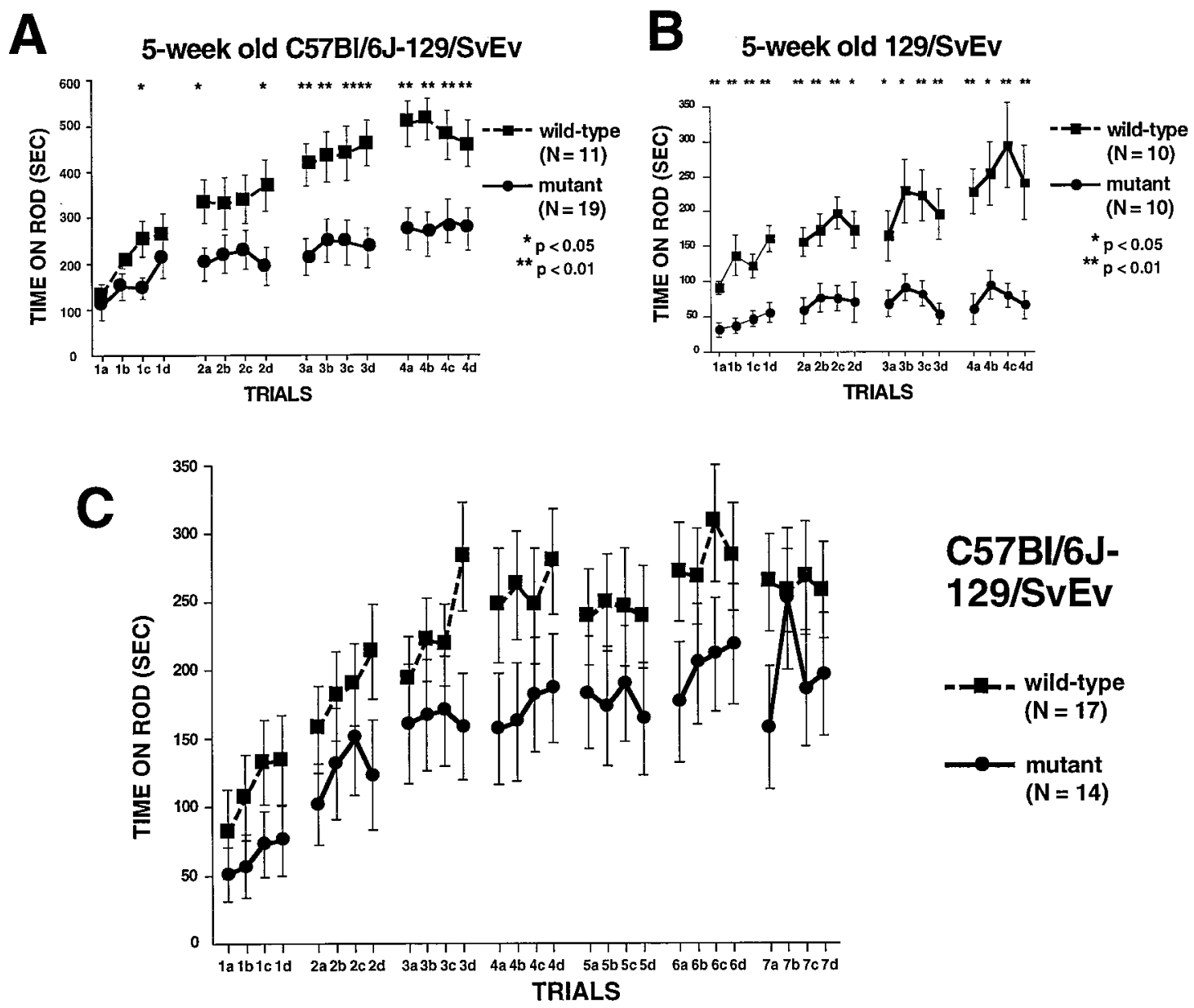

\section{C57Bl/6J- 129/SvEv}

$\mathbf{D}$

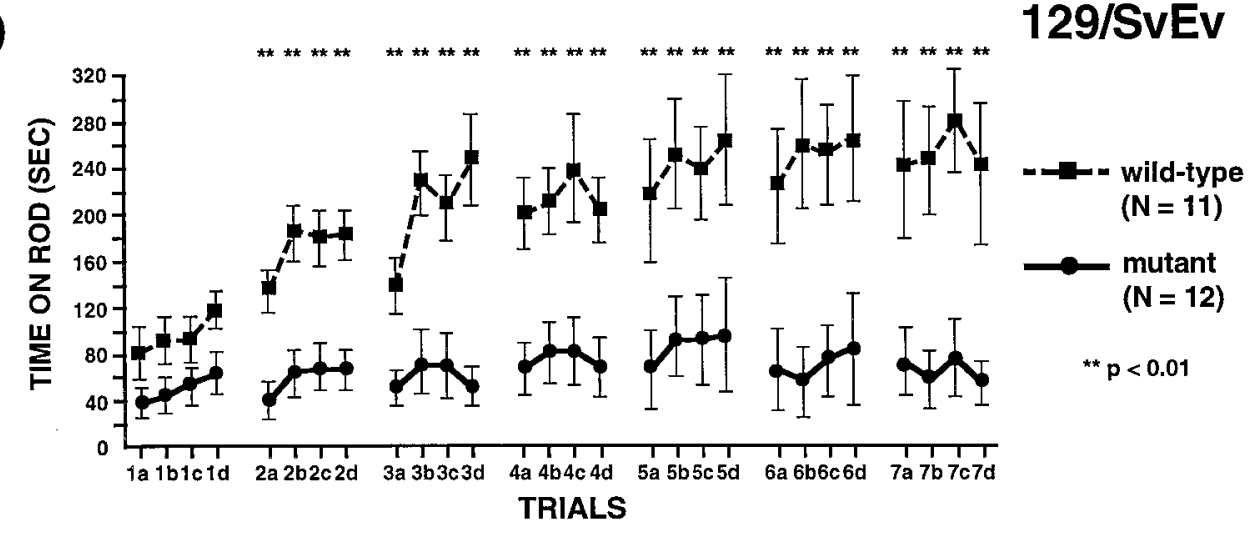

Figure 4. Analysis of Sca1 null mice on the rotating rod apparatus. Performance of 5-week-old C57Bl/6J-129/SvEv mice $(A)$, 5-week-old $129 / \mathrm{SvEv}$ mice $(B)$, 6- to 9-month-old C57Bl/6J-129/SvEv mice (C), and 6-month-old pure 129/SvEv mice $(D)$. Mice were trained four trials per day $(a-d)$ for $4(1-4)$ or 7 (1-7) d. Error bars indicate SEM.

age. Sca1 null mice of both genetic backgrounds displayed impaired performance on the rotating rod at 5 weeks (hybrid mice, $F_{(1,28)}=8.37 ; p=0.0073 ; 129 / \mathrm{SvEv}$ mice, $F_{(1,18)}=24.55 ; p<$ 0.0001 ) (Fig. $4 A, B$ ). ANOVA detected a genotype $\times$ trial interaction (hybrid mice, $F_{(15,420)}=2.85 ; p=0.0003 ; 129 / \mathrm{SvEv}$ mice, $\left.F_{(15,270)}=1.71 ; p=0.048\right)$ and also an effect of trial (hybrid mice, $F_{(15,420)}=13.05 ; p<0.0001 ; 129 / \mathrm{SvEv}$ mice, $F_{(15,270)}=4.815 ; p<$ 0.0001). Surprisingly, mutant mice of the C57Bl/6J-129/SvEv hybrid background $>6$ months old improved their performance on the rotating rod with training (Fig. $4 C$ ), and their latencies were not significantly different from those of control mice $\left(F_{(1,29)}=\right.$ $2.24 ; p=0.145)$. ANOVA with repeated measures showed an overall effect of trial $\left(F_{(27,783)}=14.75 ; p<0.0001\right)$, demonstrating improvement of both groups over time without detecting interaction $\left(F_{(27,783)}=0.96 ; p=0.517\right)$. In contrast, the performance of 6-month-old null mice from a $129 / \mathrm{SvEv}$ inbred background did not improve with time (Fig. 4D), and this impairment was not overcome even after $7 \mathrm{~d}$ of training. ANOVA with repeated measures detected a significant genotype $\times$ trial interaction $\left(F_{(27,567)}=2.44 ; p<0.001\right)$, a genotype effect $\left(F_{(1,21)}=\right.$ 
$13.83 ; p=0.001)$ showing that WT mice were significantly better than mutant mice, and an effect of trial $\left(F_{(27,567)}=4.8 ; p<0.001\right)$ where the performance of WT but not $S c a 1$ null mice improved with time $\left(F_{(27,270)}=4.74 ; p<0.001\right.$; and $F_{(27,297)}=0.75 ; p>$ 0.05 , respectively). Although the performance of 6 -month-old WT $129 / \mathrm{SvEv}$ mice was similar to that of 6- to 9-month-old WT mice of a hybrid genetic background $\left(F_{(1,24)}=0 ; p=0.952\right)$, the effect of the mutation on the $129 / \mathrm{SvEv}$ inbred background was pronounced and could not be overcome with age.

\section{Decreased PPF and normal LTP and post-tetanic potentiation in Sca1 null mice}

Because some deficits in hippocampus-dependent learning tasks have been associated with abnormalities of synaptic plasticity (Mayford et al., 1996; Altemus and Almli, 1997; Wilson and Tonegawa, 1997), we next examined synaptic transmission and activity-dependent synaptic plasticity in Scal null mice using extracellular field recording in area CA1 of hippocampal slices. All studies were conducted using WT and mutant mice from both the mixed C57Bl/6J-129/SvEv and purebred $129 / \mathrm{SvEv}$ backgrounds, which yielded similar results. Initially, normal lowfrequency synaptic transmission was examined. There were no differences between WT and mutant animals in either the ratio of presynaptic fiber volleys to postsynaptic pEPSPs, the stimulus intensity required to produce a half-maximal pEPSP, or the size of the maximal pEPSP which could be evoked (data not shown).

We next examined LTP of synaptic transmission. LTP was induced with two $1 \mathrm{sec} 100 \mathrm{~Hz}$ tetani, separated by $20 \mathrm{sec}$, and synaptic efficacy was monitored for $60 \mathrm{~min}$. No differences in LTP, assayed for $1 \mathrm{hr}$ after the tetanus, were detected between WT and mutant slices (Fig. 5A). Furthermore, no differences were detected in the transient post-tetanic potentiation (PTP) produced immediately after the high-frequency tetanus (Fig. 5A).

Finally, we analyzed paired-pulse facilitation of synaptic transmission. PPF is a form of activity-dependent synaptic plasticity that is elicited by evoking two pEPSPs, one after the another. For several hundred milliseconds after the first pulse, residual calcium in the presynaptic terminal adds to the calcium influx induced by the second pulse, producing a larger response (Wu and Saggau, 1994). We found that the degree of PPF in hippocampal slices from mutant animals was lower than that in WT slices $(p<$ 0.0001 by two-way ANOVA) (Fig. $5 B$ ). As the interpulse interval was increased, producing less PPF, this difference decreased. No paired-pulse depression was observed at any of the interpulse intervals examined.

\section{DISCUSSION}

Mice homozygous and heterozygous for the Scal null mutation, are viable, fertile, and do not display any signs of ataxia or major motor coordination abnormalities. Histological examination revealed no evidence of neurodegeneration or cerebellar atrophy in mutant mice. This is in contrast to transgenic mice overexpressing a mutant form of ataxin-1 containing 82 glutamines under the control of a Purkinje cell-specific promoter. These mice develop ataxia and Purkinje cell abnormalities that become evident at 8-10 weeks of life (Burright et al., 1995; Clark et al., 1997). These data clearly demonstrate that SCA1 is not caused by loss of function of ataxin-1, but rather by a novel function conferred on the protein by the expansion of the polyglutamine tract. Sca1 null mice of two different genetic backgrounds, mixed C57Bl/6J-129/ SvEv and pure 129/SvEv, display several neurobehavioral abnormalities: decreased exploratory behavior in the open field test,
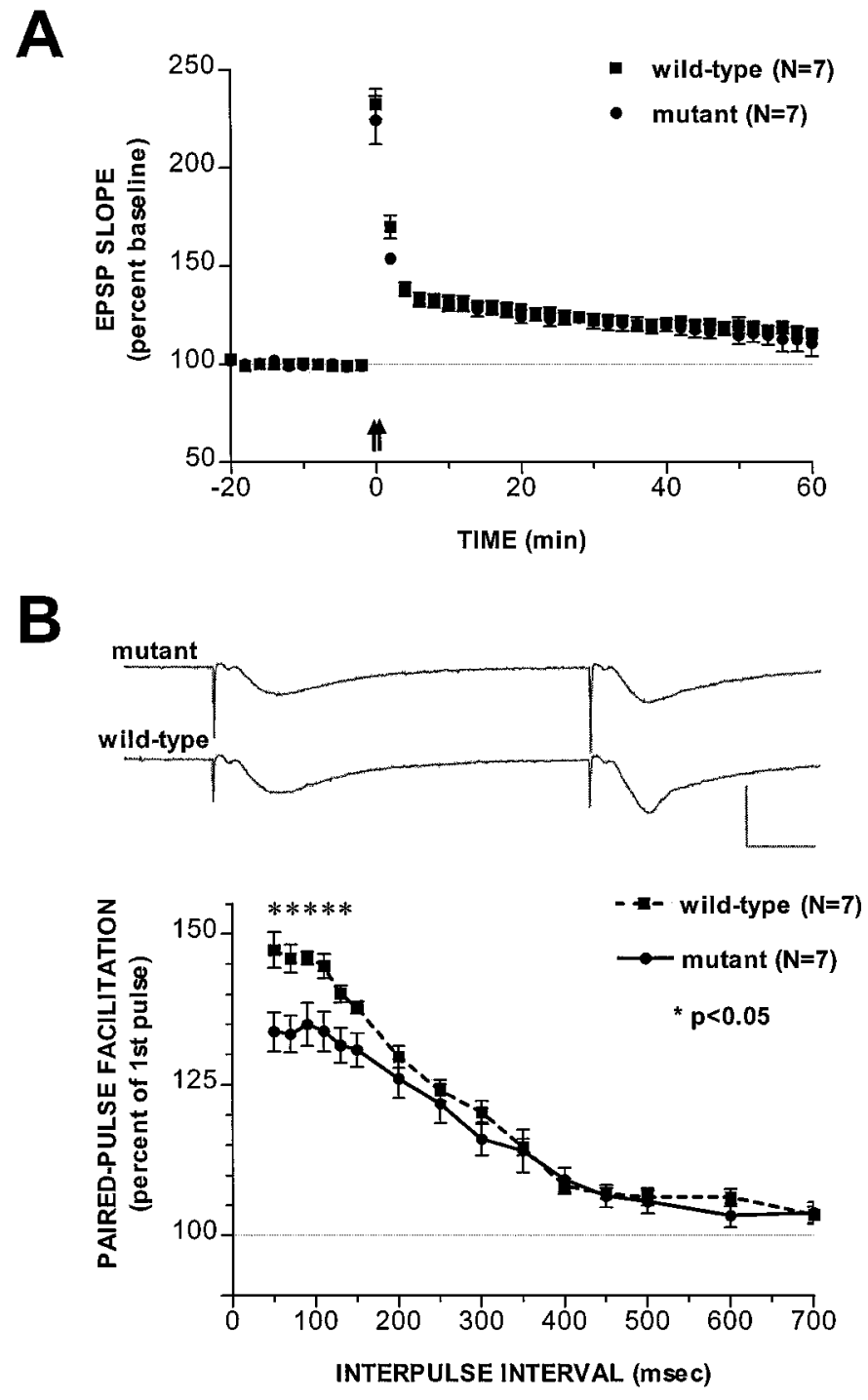

Figure 5. Synaptic transmission and activity-dependent plasticity in hippocampal area CA1 of $S c a 1$ null mice. A, LTP was induced with two $1 \mathrm{sec}$ $100 \mathrm{~Hz}$ tetani and assayed for $60 \mathrm{~min}$. Data represent the average pEPSP slope over time from seven WT animals (19 slices) and seven mutant animals (16 slices) from both mixed C57Bl/6J-129/SvEv and purebred 129/SvEv backgrounds. Error bars indicate SEM. B, PPF was elicited over a range of interpulse intervals. Data are represented as the percentage of the second EPSP slope relative to the first and are from seven WT animals (22 slices) and seven mutant animals (23 slices) from both mixed C57Bl/ $6 \mathrm{~J}-129 / \mathrm{SvEv}$ and purebred 129/SvEv backgrounds. Error bars indicate SEM. Inset, Representative PPF at 50 msec interpulse interval in mutant and WT mice. Calibration: $2 \mathrm{mV}, 9 \mathrm{msec}$.

impaired performance in the spatial version of the Morris water maze task, and impaired performance on the rotating rod apparatus. Furthermore, ataxin-1-deficient mice have diminished PPF in area CA1 of the hippocampus.

Scal mutant mice display less locomotor activity than control mice during the first interval of the first day of the open field test. In later days when novelty is no longer a factor, control and null mice behave similarly; this suggests that the overall locomotor activity of mutant mice was not impaired and that their hypoactivity reflects reduced exploratory behavior. The fact that null mice respond with increased activity to novelties in their environment argues against a complete lack of exploratory behavior. 
The elevated plus maze test confirmed decreased exploratory activity and eliminated anxiety as a possible cause. In contrast, transgenic mice overexpressing the SCA1 gene in Purkinje cells show increased exploratory activity during the first 5 min interval of the open field test (Clark et al., 1997). Because SCA1 transgenic mice are expressing mutant ataxin-1 selectively in Purkinje cells, this finding raises the possibility that the cerebellar cortex modulates exploratory behavior.

Scal null mice are severely impaired in the spatial version of the Morris water maze test. This impairment is caused neither by lack of motivation to escape from the water nor by motor deficiencies in mutant mice, because control and mutant mice covered similar distances at similar speeds in the first days of the test. The cause cannot be visual deficits, because the mice performed well on the visual-cue version of the Morris water maze. The diminished exploratory behavior and the poor performance in the spatial version of the Morris water maze test, together with decreased presynaptic short-term plasticity in area CA1 of the hippocampus, point to hippocampal dysfunction in Scal null mice. Abnormalities of exploratory behavior and spatial learning deficits have both been noted in a variety of rodents after they have suffered specific lesions to the hippocampus or disruption of genes known to be essential for hippocampal function (Moser et al., 1993; Mayford et al., 1996; Logue et al., 1997; Wilson and Tonegawa, 1997).

Although Scal null mice are not ataxic and do not show major motor coordination deficits in the tunnel test, they do perform poorly on the rotating rod apparatus. Five-week-old Sca1 null mice from both hybrid C57Bl/6J-129/SvEv and inbred 129/SvEv genetic backgrounds performed very poorly on the rotating rod when compared with control littermates. Surprisingly, 6-monthold Sca1 null mice from a mixed genetic background did not perform much worse than their wild-type littermates. In contrast, Scal null mice from a pure 129/SvEv genetic background still performed poorly on the rotating rod test after 6 months. Because it is less likely that motor incoordination can be overcome with age, these findings support the hypothesis that the impaired performance on the rotating rod by mutant mice reflects motor learning deficits. These data also suggest that this learning skill is regulated by multiple genes, because $S c a 1$ null mice that carry the mutation on different genetic backgrounds differ in ability. There is increasing evidence that some motor learning tasks are mediated by the cerebellum (Ito, 1984; Lalonde and Botez, 1990; Raymond et al., 1996); this is reasonable given that coordination of movement requires practice. Furthermore, different forms of synaptic plasticity and alterations in neurotransmission at the parallel fiber-Purkinje cell synapses (e.g., LTD) have been implicated in motor learning (for review, see Linden, 1994). Cerebellar involvement in motor learning has also been suggested by studies of mice lacking either Engrailed-2 (Gerlai et al., 1996) or the metabotropic glutamate receptors mGluR1 and mGluR4 (Aiba et al., 1994; Pekhletski et al., 1996) and transgenic mice overexpressing a human $S C A 1$ allele with 82 CAG repeats (Clark et al., 1997). Because the $S C A 1$ transgene is selectively expressed in cerebellar Purkinje cells, these data not only imply a role for the cerebellar cortex in motor learning but also indicate that ataxin-1 might be important for this process.

Analysis of LTP and PTP in area CA1 of the hippocampus in Sca1 null mice revealed no differences between control and mutant mice. Conversely, PPF was significantly decreased in Sca1 null mice of both genetic backgrounds. Presynaptic calcium has been noted to increase during normal synaptic transmission and
PPF in the CA3-CA1 synapses of hippocampus, and PPF is linearly related to the residual levels of calcium (Wu and Saggau, 1994). The PPF changes observed in Scal null mice could reflect altered presynaptic calcium handling or altered sensitivity of the neurotransmitter release machinery. In support of this hypothesis, mice lacking synapsin I, which contributes to calcium regulation of neurotransmitter release, exhibit a selective increase in PPF (Rosahl et al., 1993). The fact that normal synaptic transmission and LTP are unimpaired in Scal null mice, however, indicates that the deficits in PPF are not attributable to a complete derangement of synaptic function. Impaired learning associated with decreased PPF and normal LTP has been described previously for mice heterozygous for $\alpha$-calcium calmodulin kinase II mutation (Silva et al., 1996). However, these mice also display higher PTP. The study by Silva and collaborators (Silva et al., 1996) systematically analyzed short-term plasticity and learning in mice with four different mutations and demonstrated that either decreased PPF or decreased PTP in the presence of normal LTP leads to profound learning impairment. These data provide evidence that spatial learning impairment can be accompanied by deficits in short-term plasticity in the presence of normal LTP.

An important aspect of this study is the analysis of the effects of the Scal mutation in mice of two different genetic backgrounds (mixed C57Bl/6J-129/SvEv and inbred 129/SvEV), which both evidenced neurobehavioral abnormalities. Although WT mice from a 129/SvEv background showed less overall locomotor activity in the open field test and in the rotating rod apparatus (at 5 weeks) in comparison with WT hybrid C57Bl/6J-129/SvEv mice, we were not able to detect significant differences in the performance of these two strains in the Morris water maze test. Several independent studies have noted the influence of genetic background in the performance of various neurobehavioral tests (Wehner et al, 1996; Logue et al., 1997; Owen et al., 1997). Because there is extensive genetic variability in $129 / \mathrm{Sv}$ substrains (Simpson et al., 1997), we carefully evaluated mice from the 129/SvEv substrain derived from the ES cell line AB2.1.

We have demonstrated that mice laking ataxin-1 show no symptoms of ataxia and do not lose cerebellar Purkinje cells. Interestingly, Sca1 mutant mice display neurobehavioral abnormalities (decreased exploratory behavior in a novel environment, severe spatial learning deficits, and impaired performance on the rotating rod apparatus) without major motor coordination abnormalities or ataxia, suggesting the presence of motor learning deficits. Furthermore, Scal null mice display deficits in presynaptic plasticity in area CA1 of the hippocampus, as shown by decreased PPF. These behavioral abnormalities, which were confirmed in null mice from both $\mathrm{C} 57 \mathrm{Bl} / 6 \mathrm{~J}-129 / \mathrm{SvEv}$ hybrid and $129 / \mathrm{SvEv}$ inbred genetic backgrounds, demonstrate that SCA1 is not caused by loss of function of ataxin-1, and they are important for studies of the role of ataxin-1 in learning tasks mediated by the hippocampus and the cerebellum.

\section{REFERENCES}

Abeliovich A, Paylor R, Chen C, Kim JJ, Wehner JM, Tonegawa S (1993) PKC gamma mutant mice exhibit mild deficits in spatial and contextual learning. Cell 75:1263-1271.

Aiba A, Kano M, Chen C, Stanton ME, Fox GD, Herrup K, Zwingman TA, Tonegawa S (1994) Deficient cerebellar long-term depression and impaired motor learning in mGluR1 mutant mice. Cell 79:377-388.

Altemus KL, Almli CR (1997) Neonatal hippocampal damage in rats: long-term spatial memory deficits and associations with magnitude of hippocampal damage. Hippocampus 7:403-415.

Banfi S, Servadio A, Chung M-y, Kwiatkowski Jr TJ, McCall AE, Duvick 
LA, Shen Y, Roth EJ, Orr HT, Zoghbi HY (1994) Identification and characterization of the gene causing type 1 spinocerebellar ataxia. Nat Genet 7:513-519.

Banfi S, Servadio A, Chung M-y, Capozzoli F, Duvick LA, Elde R, Zoghbi HY, Orr HT (1996) Cloning and developmental expression analysis of the murine homolog of the spinocerebellar ataxia type 1 gene (Sca1). Hum Mol Genet 5:33-40.

Burright, EN, Clark HB, Servadio A, Matilla T, Feddersen RM, Yunis WS, Duvick LA, Zoghbi HY, Orr HT (1995) SCA1 transgenic mice: a model for neurodegeneration caused by an expanded CAG trinucleotide repeat. Cell 82:937-948.

Clark HB, Burright EN, Yunis WS, Larson S, Wilcox C, Hartman B, Matilla A, Zoghbi HY, Orr HT (1997) Purkinje cell expression of a mutant allele of SCA1 in transgenic mice leads to disparate effects on motor behaviors followed by a progressive cerebellar dysfunction and histological alterations. J Neurosci 17:7385-7395.

Crusio WE, Schwegler H, van Abeelen JH (1989) Behavioral responses to novelty and structural variation of the hippocampus in mice. I. Quantitative-genetic analysis of behavior in the open-field. Behav Brain Res 32:75-80.

Gerlai R, Millen KJ, Herrup K, Fabien K, Joyner Al, Roder J (1996) Impaired motor learning performance in cerebellar En-2 mutant mice. Behav Neurosci 110:126-133.

Gossen M, Scmitt I, Obst K, Wahle P, Epplen JT, Riess O (1996) cDNA cloning and expression of rsca1, the rat counterpart of the human spinocerebellar ataxia type 1 gene. Hum Mol Genet 5:381-389.

Ito M (1984) The modifiable neuronal network of the cerebellum. Jpn J Physiol 34:781-792.

Jones BJ, Roberts DJ (1968) The quantitative measurement of motor incoordination in naive mice using an accelerating Rota-Rod. J Pharm Pharmacol 20:302-304.

Lalonde R, Botez MI (1990) The cerebellum and learning processes in animals. Brain Res Rev 15:325-332.

Linden DJ (1994) Long-term synaptic depression in the mammalian brain. Neuron 12:457-472.

Lister RG (1987) The use of a plus-maze to measure anxiety in the mouse. Psychopharmacology 92:180-185.

Logue SF, Paylor R, Wehner JM (1997) Hippocampal lesions cause learning deficits in inbred mice in the Morris water maze and conditioned-fear task. Behav Neurosci 111:104-113.

Matzuk MM, Finegold MJ, Su J-G, Hsueh AJW, Bradley A (1992) $\alpha$-Inhibin is a tumour-suppressor gene with gonadal specificity in mice. Nature 360:313-319.

Mayford M, Bach ME, Huang YY, Wang L, Hawkins RD, Kandel ER (1996) Control of memory formation through regulated expression of a CaMKII transgene. Science 274:1678-1683.

Morris RG, Garrud P, Rawlins JN, O'Keefe J (1982) Place navigation impaired in rats with hippocampal lesions. Nature 297:681-683.

Moser E, Moser MB, Andersen P (1993) Spatial learning impairment parallels the magnitude of dorsal hippocampal lesions, but is hardly present following ventral lesions. J Neurosci 13:3916-3925.

Orr H, Chung M-y, Banfi S, Kwiatkowski Jr TJ, Servadio A, Beaudet AL, McCall AE, Duvick LA, Ranum LPW, Zoghbi HY (1993) Expansion of an unstable trinucleotide $(\mathrm{CAG})$ repeat in spinocerebellar ataxia type 1. Nat Genet 4:221-226.

Owen EH, Logue SF, Rasmussen DL, Wehner JM (1997) Assessment of learning by the Morris water task and fear conditioning in inbred mouse strains and F1 hybrids: implications of genetic background for single gene mutations and quantitative trait loci analyses. Neuroscience 80:1087-1099.

Pekhletski R, Gerlai R, Overstreet LS, Huang X-P, Agopyan N, Slater NT, Abramow-Newerly W, Roder JC, Hampson DR (1996) Impaired cerebellar synaptic plasticity and motor performance in mice lacking the mGluR4 subtype of metabotropic glutamate receptor. J Neurosci 16:6364-6373.

Raymond JL, Lisberger SG, Mauk MD (1996) The cerebellum: a neuronal learning machine? Science 272:1126-1131.

Roberson ED and Sweatt JD (1996) Transient activation of cyclic AMPdependent protein kinase during hippocampal long-term potentiation. J Biol Chem 271:30436-30441.

Rosahl TW, Geppert M, Spillane D, Herz J, Hammer RE, Malenka RC, Südhof TC (1993) Short-term synaptic plasticity is altered in mice lacking synapsin I. Cell 75:661-670.

Servadio A, Koshy B, Armstrong D, Antalffy B, Orr HT, Zoghbi HY (1995) Expression analysis of the ataxin-1 protein in tissues from normal and spinocerebellar ataxia type 1 individuals. Nat Genet 10:94-98.

Silva AJ, Paylor R, Wehner JM, Tonegawa S (1992) Impaired spatial learning in $\alpha$-calcium-calmodulin kinase II mutant mice. Science 257:206-211.

Silva AJ, Rosahl TW, Chapman PF, Marowitz Z, Friedman E, Frankland PW, Cestari V, Cioffi D, Südhof TC, Bourtchuladze R (1996) Impaired learning in mice with abnormal short-lived plasticity. Curr Biol 6:1509-1518.

Simpson EM, Linder CC, Sargent EE, Davisson MT, Mobraaten LE, Sharp JJ (1997) Genetic variation among 129 substrains and its importance for targeted mutagenesis in mice. Nat Genet 16:19-27.

Wehner JM, Bowers BJ, Paylor R (1996) The use of null mutant mice to study complex learning and memory processes. Behav Genet 26:301-312.

Wilson MA, Tonegawa S (1997) Synaptic plasticity, place cells and spatial memory: study with second generation knockouts. Trends Neurosci 20:102-206.

Wu LG, Saggau P (1994) Presynaptic calcium is increased during normal synaptic transmission and paired-pulse facilitation, but not in long-term potentiation in area CA1 of hippocampus. J Neurosci 14:645-654.

Zoghbi HY, Orr HT (1995) Spinocerebellar ataxia type 1. Semin Cell Biol 6:29-35. 